\title{
Review
}

\section{A study of precipitation variability in the Duero Basin (Iberian Peninsula)}

\author{
Liliana Caramelo ${ }^{\mathrm{a} *}$ and M. Dolores Manso Orgaz \\ a Departamento de Física, Universidade de Trás-os-Montes e Alto Douro, Apartado 1013, 5000-911 Vila Real, Portugal \\ b Departamento de Física, Universidade de Aveiro, Campus Universitário de Santiago, 3810-193 Aveiro, Portugal
}

\begin{abstract}
:
Spatial and temporal average behaviour of winter precipitation in the Duero basin (DB) were analysed for 1958-1993. Monthly observed data (observed data) from 34 weather stations and a subset of daily precipitation data from the NCEP/NCAR reanalysis project (reanalysis data) were used.

The spatial variability of winter precipitation was examined using principal component analysis (PCA) for both types of data. The winter precipitation fields are well represented by the first three principal components (PC), which describe $81 \%$ and $87 \%$ of the total variance for the observed and reanalysis data, respectively. The relationship between the three leading PCs and circulation patterns was also investigated. The PC1 is related to the North Atlantic Pattern (NAO), East Atlantic Pattern (EA) and Pacific North American Pattern (PNA). The PC2 is related to the East Atlantic/West Russia Pattern (EAWR), while the PC3 depends mainly on Scandinavia Pattern (SCAND) influences.

The reanalysis data were used to calculate a 10-day period to study the intra-annual variation (S-mode of PCA) and the spatial distribution of those precipitation amounts during the year (T-mode of PCA). For the intra-annual variation of precipitation, two modes statistically significant were obtained. The first mode was characterized by a broad maximum that extended from mid October to early April, and a minimum that extended from early May to September. The second mode exhibited two maxima and a minimum. The first maximum occurred in late February and the second maximum extended from early April to June. The minimum extended from mid July to early February. For the spatial distribution of precipitation, we obtained three patterns. The 'winter' pattern, which showed a maximum over the western area, the 'spring' pattern with a maximum over the eastern area, and the 'autumn' with a maximum over the easternmost edge of the basin. Copyright (c) 2006 Royal Meteorological Society
\end{abstract}

KEY WORDS precipitation variability; principal component analysis; 10-day period

Received 4 February 2005; Accepted 11 July 2006

\section{INTRODUCTION}

In the past few years, investigators have been concerned with climate variability. Knowledge of the nature and causes of precipitation variability is desirable due to its impact on human activities and natural resources. In recent years, several studies of the precipitation variability and its relationships to anomalies in the macroscale circulation have been undertaken as is evident from the articles available in the literature (e.g. Cahalan, 1983; Fraedrich and Muller, 1992; Drosdowsky, 1993; Hogg, 1995; Hurrel and van Loon, 1995; Kutiel et al., 1996; Matayo et al., 2000; Zhou and Lau, 2001). Hurrel and van Loon (1995) analysed the effect of teleconnection indices on Northern Hemisphere temperature and precipitation. Marshall et al. (2001) attributed climatic variability in the North Atlantic sector to three interconnected phenomena: the North Atlantic Ocean Pattern (NAO), the

* Correspondence to: Liliana Caramelo, Departamento de Física, Universidade de Trás-os-Montes e Alto Douro, Apartado 1013, 5000-911 Vila Real, Portugal. E-mail: lcaramel@utad.pt
$\mathrm{AO}$ and the Atlantic meridional overturning circulation. Regarding the Iberian Peninsula, Rodríguez-Puebla et al. (1998 and 1999) investigated the spatial and temporal variability of annual precipitation. They also analysed the relationship between the annual precipitation and the following circulation patterns: East Atlantic Pattern (EA), NAO, SOI and Scandinavia pattern (SCAND). Zorita et al. (1992 and 1995) demonstrated the effect of NAO and atmospheric conditions on the Iberian rainfall during the winter season. On the other hand, Rodó et al. (1997) demonstrated that most of the Iberian Peninsula is under the influence of the NAO in winter. Rodríguez-Puebla et al. (2001) also investigated the winter precipitation over the Iberian Peninsula and its relationship to circulation indices. Nieto et al. (2004) studied the variability patterns obtained with observed winter precipitation data, data from NCEP-NCAR reanalysis project and data from two global climatic models, on the Iberian Peninsula. In addition, Goodess and Jones (2002) obtained the association between circulation frequencies and Iberian rainfall. 
There has recently been a growing interest in the study of precipitation variability on a much smaller scale. For example, in Southern Spain, Rodrigo et al. (2000) examined the relationship between the NAO and rainfall variability on decadal to centennial scales. Saénz et al. (2001) analysed the inter-annual variability of winter precipitation in the Northern Iberian Peninsula, and Lana et al. (2004) studied the spatial and temporal variability of the daily rainfall regime in Catalonia. Most of all the aforementioned studies deal with the characteristics of precipitation variability and define rainfall regimes on the basis of the seasonal or annual values. However, a more detailed analysis by making use of a variable that differs from annual and seasonal amount contributes, with different points of view, to our knowledge of the precipitation regime in the Duero basin (DB). Ten-day data values (10-DDV) of precipitation were computed from daily amounts and the analyses of spatial organization of precipitation fields were performed. The climatic seasons can be defined on the basis of similar space variability and their distribution during the year using principal component analysis (PCA). In view of this, the present study sets out to present a definition of the homogeneous season based on PCA of 10-DDV, similar to the work of Bartzokas et al. (2003).

It is well known that the Iberian precipitation regime is characterized by high variability in both space and time domains (Esteban-Parra et al., 1998). The DB is the largest basin in the Iberian Peninsula and it records the greatest amount of precipitation in the Iberian Peninsula. Therefore the impact of precipitation variability is related to social and economic activities such as water resources management in particular, hydroelectric production, agricultural production (wine production as Porto wine), land use and tourism. Furthermore the study of the precipitation variability on a regional scale plays a significant role. Of great interest is the identification of spatial distributions and patterns, such as those associated with intense precipitation in view of the future application of a limited area model to the DB. The other aim of this work consists in studying the spatial variability of winter precipitation in the DB and should be the starting point for determining how this regime is influenced by the main orographic features and by the atmospheric circulation patterns. For that purpose, PCA (S-mode) and correlation relationship were performed with winter precipitation data (observed and reanalysis data) to investigate the relationship between the winter precipitation and circulations' patterns (NAO, EA, PNA, East Atlantic/West Russia Pattern (EAWR), and SCAND).

This paper is organized as follows: after this introduction, a summary description of the study area is presented in Section 2. Section 2 also reports on the data sets and the methods. In Section 3, the characteristics of the spatial variability of the winter and precipitation amount are examined. The conclusions are presented in Section 4. The methods used in this study are referred to without explanation because they are well known and have often been described.

\section{DATA}

\subsection{Study area}

The DB is located in the Iberian Peninsula and is enclosed by latitudes $40.3^{\circ}-43.2^{\circ} \mathrm{N}$ and longitudes $1.7^{\circ}-8.7^{\circ} \mathrm{W}$ (Figure 1). This area is located in the wet temperate zone of southern Europe. The most important aspects of climate in the DB are its localization, which is relative to the atmospheric circulation patterns, its orography (Figure 1) and its proximity to the Atlantic Ocean.

The winter is dominated by the depressions of westerly circulation and by meridional circulation. More than $40 \%$ of the annual precipitation occurs during winter in the western zone of the basin. The summer is dominated by the Azores High. Less than $16 \%$ of the annual precipitation occurs during summer in the coastal area. In spring, precipitation is particularly due to local storms that are generated by local convection. More than $28 \%$ of the annual precipitation occurs during spring in the eastern region of the basin.

Relative to the orography, the DB is bounded by the Cantabrico mountain system (about $2648 \mathrm{~m}$ height) to the north, the Iberico mountain system (about $2313 \mathrm{~m}$ height) to the east and the Central mountain system (about $2592 \mathrm{~m}$ height) in the south and the Galaico-Portuguese mountain system. The Atlantic Ocean is the western boundary. As a result of this distribution of orography and the Atlantic origin, many synoptic disturbances contribute to a spatial variability in the precipitation amounts (Trigo et al., 2004).

\subsection{Data sources}

2.2.1. Observed data. Observed precipitation data were obtained from the National Institute of Meteorology of Spain and from the Water Institute of Portugal (http://www.inag.pt).

The observed data consists of monthly precipitation totals recorded at 34 weather stations located in Spain and Portugal, both within and without the DB, for the 1958-1993 period (Figure 2). The 34 stations have relatively few missing data, less than $5 \%$ of the total number of monthly values. Thus, the missing data were filled using an interpolation method similar to the one proposed by Peterson and Easterling (1994).

From the monthly precipitation time series, winter precipitation time series were calculated as the total amount of precipitation from December of the preceding year to February of the following year.

2.2.2. Data from NCEP/NCAR reanalysis project. A 24-point grid was considered, from $0.000^{\circ}$ to $9.375^{\circ} \mathrm{W}$ of longitude and from $39.0470^{\circ}$ to $44.7620^{\circ} \mathrm{N}$ of latitude using data from the National Centers for Environmental Prediction/National Center for Atmospheric Research (NCEP/NCAR) reanalysis project.

To study winter precipitation variability, monthly time series were calculated from the daily time series. Winter precipitation values were estimated as the total amount 


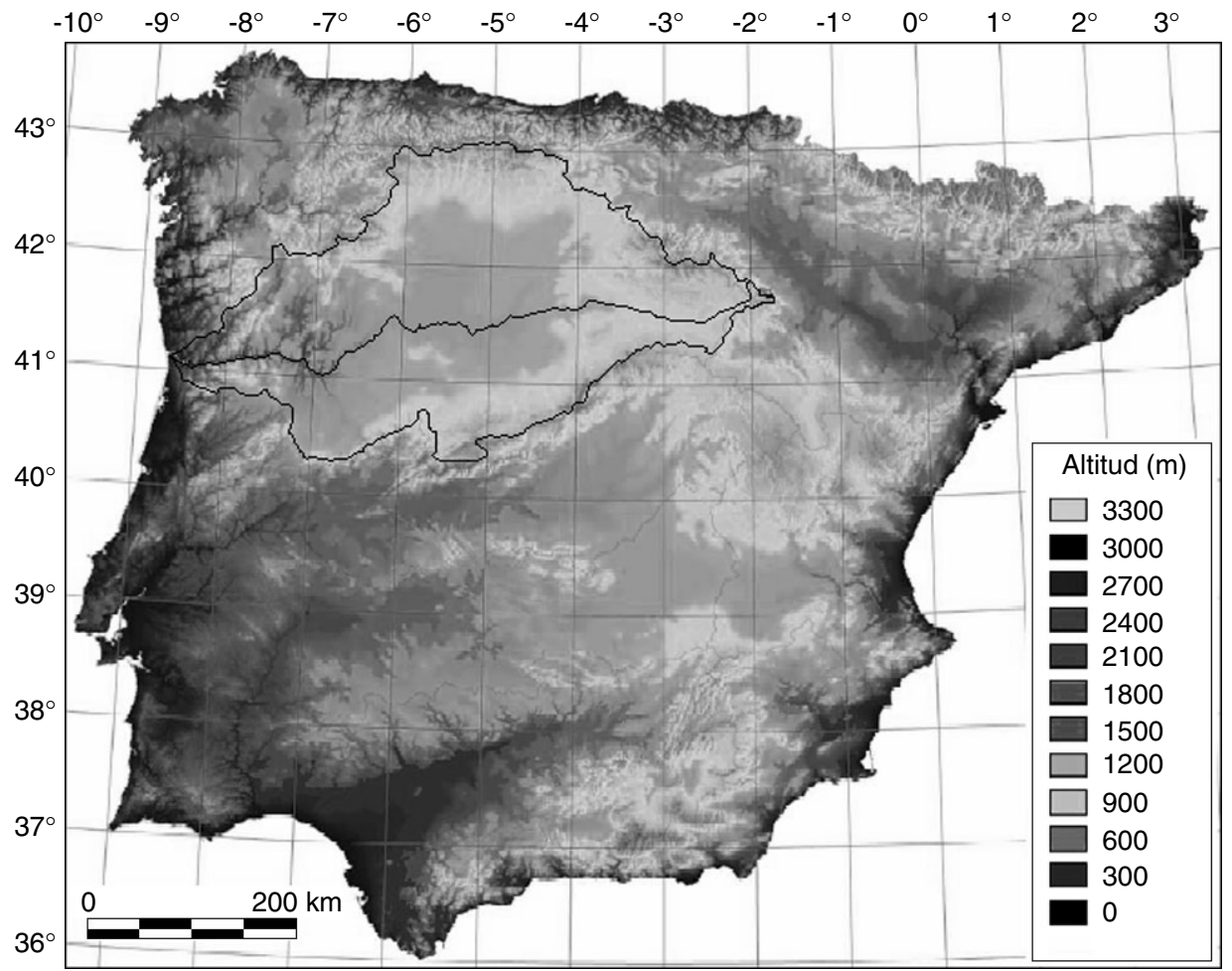

Figure 1. Location of the Duero basin and the main features of Iberian Peninsula orography (Ninyerola et al., 2005).

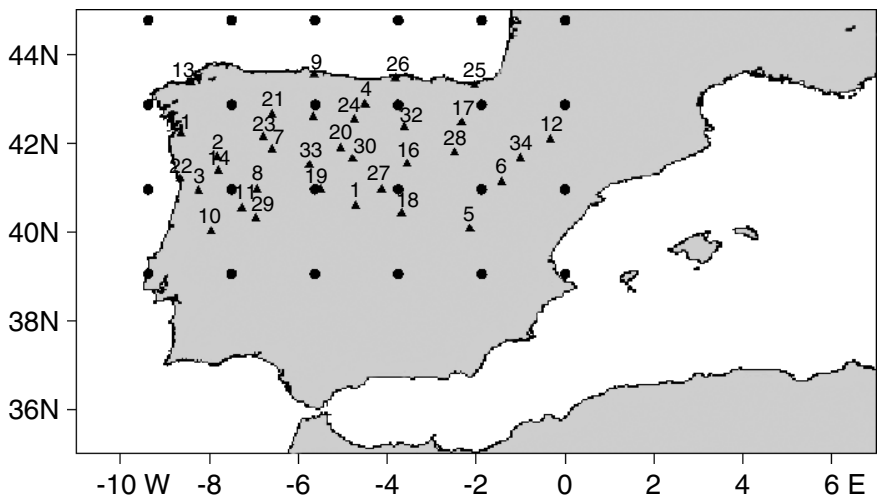

Figure 2. Location of meteorological observational network

$(\mathbf{\Delta})$ and grid points of reanalysis data

) used in this study.

of precipitation from December of the previous year to February.

For the study of intra-annual variability and spatial distribution of precipitation the data consists of 10-DDV (three values per month) of precipitation amount from 1958 to 1993. The 10-DDV was averaged over the 36 years and the mean intra-annual variation amounts consisting of 36 values were constructed for each grid point. Thus, the data sets consist of 36 mean 10-DDV for the 24-grid point.

\subsection{Methods of analysis}

Table I summarizes the statistics of observed precipitation data, as well as, Mann-Whitney test and Wald-Wolfowitz test results.

The results reveal that approximately $71 \%$ of the winter precipitation time series can be considered as mesokurtic because the kurtosis values are between the critical values $(-1.056$ and 1.502) (Ardanuy and Soldevilla, 1992). Most of the time series $(65 \%)$ are positively skewed and this means that the greatest winter precipitation values are less frequent.

The data were also subjected to statistical quality control. Homogeneity analysis has been made with the Mann test and the Wald-Wolfowitz test (Sneyers, 1975, 1990). The Wald-Wolfowitz test indicated no significant correlation in the time series of the winter precipitation for 31 of the 34 series investigated. Only three series showed significant serial correlation in the winter precipitation values. Trends of decreasing winter precipitation were observed for $38 \%$ of the time series, although the results of the Mann test showed that these trends were not statistically significant. Therefore, there is no clear evidence from statistical analysis of the observed time series 
Table I. Statistical parameters of the observational winter time series.

\begin{tabular}{|c|c|c|c|c|c|c|c|c|}
\hline & Satation & $\begin{array}{l}\text { ELE } \\
(\mathrm{m})\end{array}$ & $\begin{array}{c}\mathrm{RM} \\
(\mathrm{mm})\end{array}$ & SD & SK & KT & $\begin{array}{c}\mathrm{u} \\
(\mathrm{r})\end{array}$ & $\begin{array}{l}\mathrm{u} \\
(\mathrm{t})\end{array}$ \\
\hline 1 & Aldea Rey Niño & 1160 & 168.4 & 78.4 & 0.108 & -1.337 & 0.046 & -1.747 \\
\hline 2 & Alturas Barroso & 1279 & 751.3 & 383.9 & 0.429 & -1.017 & -0.056 & -0.952 \\
\hline 3 & Arouca & 300 & 661.1 & 354.2 & 0.835 & 0.356 & -0.519 & -1.434 \\
\hline 4 & Cervera Pisuerga & 1013 & 345.5 & 185.3 & 1.163 & 1.443 & -0.740 & -0.611 \\
\hline 5 & Cuenca & 956 & 157.6 & 79.0 & 0.115 & -0.846 & 0.691 & -2.03 \\
\hline 6 & Daroca & 779 & 82.3 & 36.4 & 0.258 & -0.529 & 0.413 & -1.974 \\
\hline 7 & Deilão & 870 & 303.4 & 155.6 & 0.456 & -0.105 & -0.163 & -1.860 \\
\hline 8 & Escalhão & 615 & 189.3 & 92.9 & 0.355 & -0.511 & 0.771 & -2.00 \\
\hline 9 & Gijón & 10 & 285.0 & 104.4 & -0.129 & -0.237 & $1.690^{*}$ & -1.747 \\
\hline 10 & Gralheira & 1100 & 965.1 & 506.2 & 1.007 & 0.909 & 0.070 & -1.576 \\
\hline 11 & Guarda & 1019 & 368.2 & 164.0 & 0.026 & -0.734 & 0.444 & -2.627 \\
\hline 12 & Huesca & 541 & 127.1 & 59.0 & 0.694 & 0.924 & 1.109 & -3.053 \\
\hline 13 & La Coruña & 57 & 365.0 & 160.7 & 1.005 & 1.649 & -0.060 & -1.264 \\
\hline 14 & Lamas Olo & 1025 & 738.5 & 531.1 & 1.555 & 3.250 & $2.002^{*}$ & -3.423 \\
\hline 15 & Léon & 913 & 182.6 & 101.0 & 1.231 & 2.187 & 0.343 & -2.030 \\
\hline 16 & Linares Arroyo & 911 & 115.4 & 53.0 & 1.130 & 2.778 & -0.225 & -0.951 \\
\hline 17 & Logroño & 352 & 85.8 & 36.1 & 0.157 & -0.678 & 1.114 & -1.804 \\
\hline 18 & Madrid & 582 & 140.4 & 70.0 & 0.181 & -0.687 & 0.462 & -2.088 \\
\hline 19 & Matacan & 790 & 109.0 & 53.3 & 0.365 & -0.103 & 0.198 & -2.485 \\
\hline 20 & Medina Rioseco & 749 & 122.8 & 66.8 & 0.650 & -0.013 & 0.087 & -2.173 \\
\hline 21 & Ponferrada & 550 & 235.6 & 139.8 & 1.483 & 2.345 & 0.279 & -0.696 \\
\hline 22 & Porto & 90 & 486.5 & 224.7 & 0.716 & 0.584 & -0.465 & -1.434 \\
\hline 23 & Presa Cardena & 1600 & 566.6 & 307.5 & 1.320 & 1.987 & -0.425 & -0.241 \\
\hline 24 & Saldaña & 912 & 178.6 & 86.2 & 0.808 & 0.587 & -0.111 & -1.065 \\
\hline 25 & San Sebastián & 259 & 439.0 & 147.0 & 0.227 & -0.201 & $2.332^{*}$ & -1.150 \\
\hline 26 & Santander & 65 & 359.3 & 116.3 & -0.481 & -0.309 & 1.957 & -1.548 \\
\hline 27 & Segóvia & 1005 & 119.8 & 53.4 & 0.357 & -0.631 & -0.492 & -1.179 \\
\hline 28 & Soria & 1082 & 136.4 & 70.4 & 1.123 & 2.666 & 0.552 & -2.173 \\
\hline 29 & Vale Espinho & 885 & 546.9 & 298.7 & 0.562 & 0.333 & 0.211 & -1.406 \\
\hline 30 & Valladolid & 735 & 125.7 & 65.0 & 0.704 & 0.097 & -0.065 & -1.434 \\
\hline 31 & Vigo & 255 & 791.7 & 363.4 & 0.568 & 0.185 & -0.567 & -1.179 \\
\hline 32 & Villafria & 881 & 166.8 & 88.8 & 1.267 & 2.037 & 0.481 & -2.400 \\
\hline 33 & Zamora & 667 & 118.4 & 66.6 & 0.682 & -0.137 & 1.526 & -2.713 \\
\hline 34 & Zaragoza & 247 & 68.1 & 35.5 & 0.660 & 0.310 & -0.648 & -1.179 \\
\hline
\end{tabular}

ELE, elevation; RM, winter mean precipitation (mm); SD, standard deviation; SK, skewness; KT, kurtosis; u (r), Wald-Wolfowitz statistics test; $\mathrm{u}(\mathrm{t})$, Mann statistics test.

to suggest an inhomogeneity in the winter precipitation series.

To study the spatial variability, the PCA was used (Atchley and Bryant, 1975; von Storch and Zwiers, 1999). This method allows a field to be decomposed in spatial patterns and in temporal coefficients. The spatial patterns also called empirical orthogonal functions (EOFs) permit to obtain a regionalization, i.e. to identify homogeneous zones with similar variation patterns. The PCA technique is useful because it enables the reduction of dimensionality of the data while retaining most of the precipitation variation. Thus, the S-mode of PCA (Jolliffe, 1986; Preisendorfer, 1988) was applied to the data matrices. Stations or grid points with similar variation of winter precipitation were detected and clustered, revealing the sub-areas of the basin. Varimax orthogonal rotation is the option used to avoid some of the domain shape dependence (Richman, 1986) and to obtain stable and physically meaningful patterns (von Storch, 1995).
In the study of intra-annual variability, S-mode and T-mode of PCA were applied to the 10-DDV of precipitation as in Bartzokas et al. (2003). The S-mode enabled us to obtain zones with identical variation of precipitation, while the T-mode revealed the seasons of the year from a precipitation point of view. For the selection of the number of Principal components (PCs), we used the scree test that was proposed by Cattel (1966) and reviewed by Browen (1968).

As is well known, the variability of the precipitation series must be due to physical causes that in general are related to anomalies in the large-scale circulation of atmosphere. Therefore, the teleconnection indices, centres of action of anomalies in the tropospheric geopotencial field, proposed by Barnston and Livezey (1987) were considered to analyse the relationship between the precipitation and the anomalies in the large-scale general circulation. The data of NAO, EA, PNA, EAWR and SCAND were derived from 
the database of the Climate Diagnostics Center (CPC, http://www.cpc.ncep.noaa.gov/).

\section{RESULTS}

\subsection{Characterization of winter precipitation}

To analyse the main characteristics of winter precipitation, we obtained the mean value of winter precipitation, in the period considered for both types of data (observed and reanalysis data). Figure 2 shows the location of meteorological stations $(\boldsymbol{\Delta})$ and the grid points of reanalysis data (•) used in this research.

The spatial distribution of mean winter precipitation for observed data is depicted in Figure 3(a) for the period 1958-1993. The spatial distribution is based on data from 34 stations of the meteorological network used in this study. Contrasts are illustrated between western and eastern areas. The mountains that separate coastal and inland sites play an important role as blocking factors for zonal moisture transports. The ability of mountains in the basin to modify the spatial structure of precipitation is clear in steep meridional gradients of precipitation. Generally, stations situated on the Atlantic coast are characterized by the highest values, while the lowest values are observed on the eastern area of the DB. In the $368 \mathrm{~km}$ from west to east, winter precipitation decreases from $600 \mathrm{~mm}$ to $200 \mathrm{~mm}$. Figure 3(b) shows also the mean spatial distribution for the reanalysis data.

The line corresponding to $200 \mathrm{~mm}$ separates the zone of greater precipitation and the zone of lesser precipitation in both figures. The greatest precipitation is observed in the western zone, while the lowest is recorded in the eastern area. The spatial distribution shown in these figures tends to be similar. Nevertheless, the results obtained with reanalysis data in the western area are smaller than the ones obtained with observed data. Such differences in the mean value of winter precipitation are probably due to the different spatial resolutions of the grids used in this study.

\subsection{Variability of winter precipitation}

To study winter variability we applied the PCA (Smode) to observed data, as well as to reanalysis data. The empirical orthogonal functions were obtained to characterize the modes of variability and to determine which of them has the periodic characteristics of the subregion where it was more influenced. To investigate the relationship between winter precipitation and anomalies in the dominant patterns of atmospheric variability, we performed the correlation between teleconnection indices and PCs of winter precipitation.

\subsection{Spatial variability of winter precipitation}

The first component accounts for $67.5 \%$ and $60.8 \%$ of the winter precipitation variance for observed and reanalysis data, respectively (Table II). The EOF1 reveals positive loadings everywhere (Figures 4(a) and 5(a)). The highest values appear in the western zone in the mountain system located in the north-west of Portugal (Galaico-Portuguese mountain system) and in the inner part of the DB, a large plain characterized by a height of $700 \mathrm{~m}$. This component represents the variability of winter precipitation in the direction of the western part of the DB.

Zorita et al. (1992) and Nieto et al. (2004) have obtained similar results for EOF1 of winter precipitation in the Iberian Peninsula. The pattern obtained by Rodríguez-Puebla et al. (1998) also exhibits positive
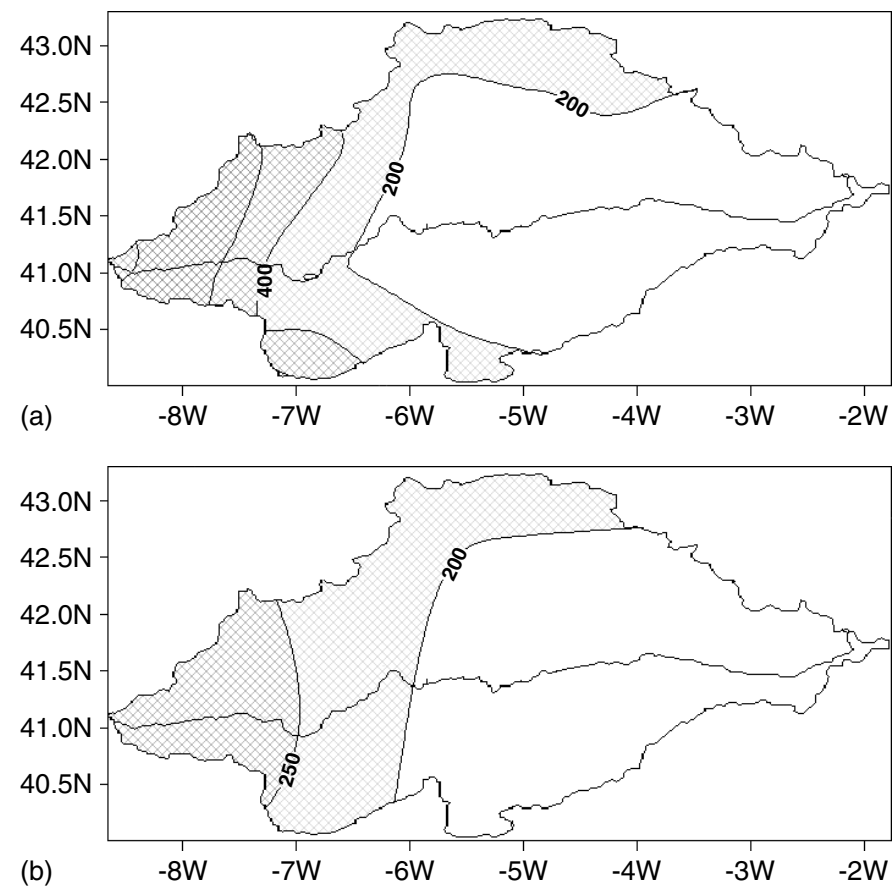

Figure 3. Spatial distribution of winter precipitation over DB for the 1958-1993 period for (a) observed data; (b) reanalysis data. 
Table II. (a) Percentage of total variance of observed winter precipitation; (b) percentage of total variance of reanalysis winter precipitation; (c) percentage of total variance of decades values of precipitation obtain with S-mode of PCA; (d) percentage of total variance of decades values of precipitation obtain with T-mode of PCA.

\begin{tabular}{lcccc}
\hline & $\begin{array}{c}\text { (a) } \\
\text { Percentage of total } \\
\text { variance }\end{array}$ & $\begin{array}{c}\text { Percentage of total } \\
\text { variance }\end{array}$ & $\begin{array}{c}\text { (c) } \\
\text { Percentage of total } \\
\text { variance }\end{array}$ & $\begin{array}{c}\text { (d) } \\
\text { Percentage of } \\
\text { total variance }\end{array}$ \\
\hline EOF1 & 67.5 & 60.8 & 56.3 & 53.2 \\
EOF2 & 8.4 & 16.7 & 30.8 & 33.7 \\
EOF3 & 5.3 & 9.9 & - & 8.8 \\
\hline
\end{tabular}
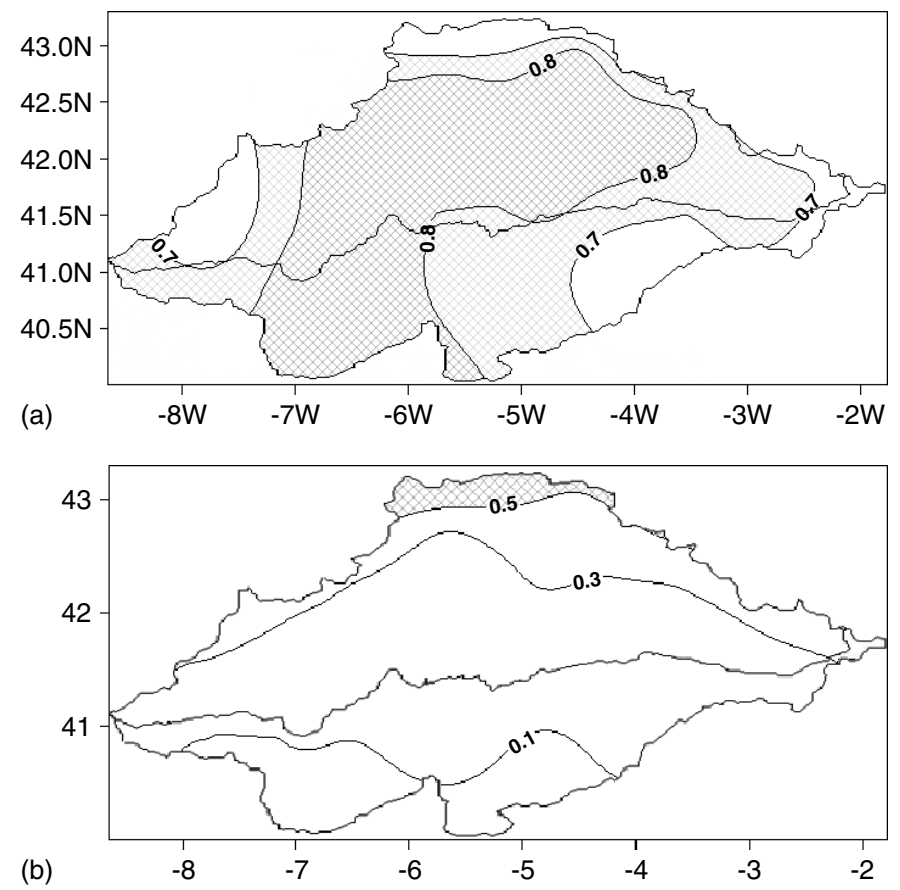

(b)

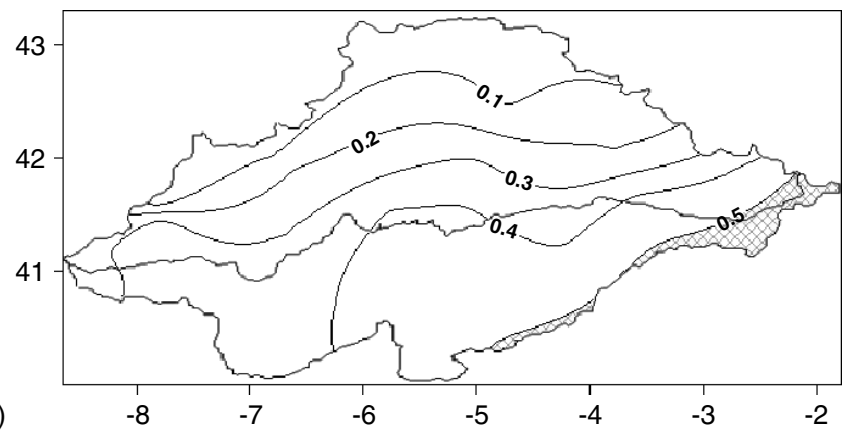

Figure 4. EOFs of winter precipitation data: (a) EOF1 observed; (b) EOF2 observed (c) EOF3 observed.

values over entire Iberia, with higher values towards the western regions.

The corresponding principal component 1 (PC1), for both data, is negatively correlated with January NAO (NAO1), winter NAO (DJF-NAO) and November PNA (PNA11) (Table III). The negative relationship between NAO and precipitation was expected according to previous results obtained by Ródo et al. (1997) and RodríguezPuebla et al. (1998) for the entire Iberian Peninsula. This component is also positively correlated with January EA (EA1) (Table III). Rodríguez-Puebla et al. (1998) obtained a significant correlation between PC1 for annual precipitation and April EA (EA4).
The second component explains $8.4 \%$ and $16.7 \%$ of the total variance for observed and reanalysis data. In the EOF2 pattern, high values appear in the north zone (for observed data) and the north-eastern zone (for reanalysis data) in the Cantabrico mountain system, while lower values are observed in the south zone in the northern Central mountain system (Figures 4(b) and 5(b)). For both data, this component divides the basin into two regions: the north and the south.

Relative to this pattern, for winter precipitation, Zorita et al. (1992) obtained a dipolar structure with positive and negative values being separated by a line connecting the southern end of Portugal and the Bay of Biscay. 

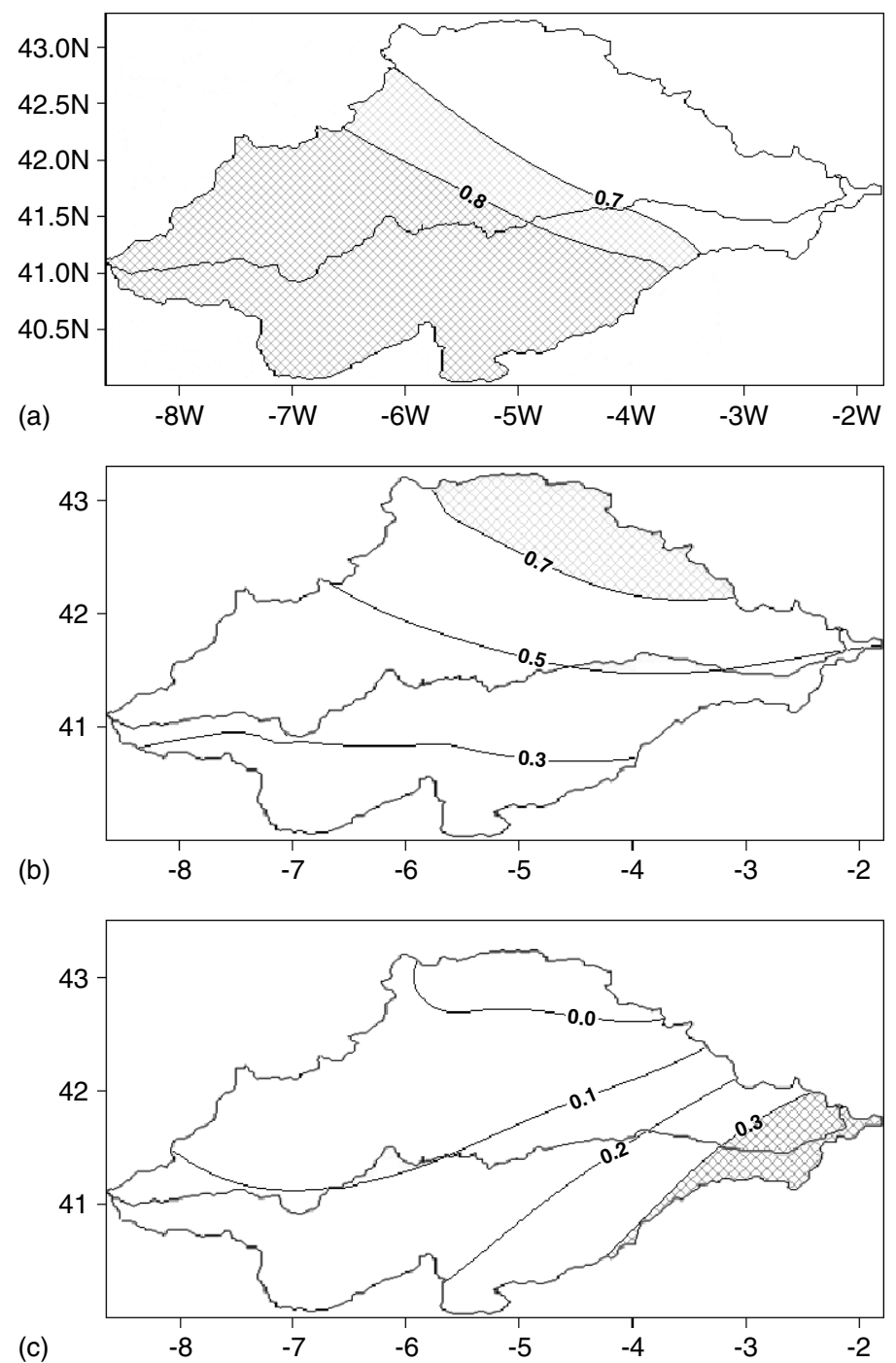

Figure 5. EOFs of winter precipitation data: (a) EOF1 reanalysis; (b) EOF2 reanalysis (c) EOF3 reanalysis.

Table III. Correlation coefficients between PCs of winter precipitation corresponding to the observed data (PCs-obs), reanalysis data (PCs-rea) and the teleconnection indices.

\begin{tabular}{lcccccc}
\hline & PC1-obs & PC2-obs & PC3-obs & PC1-rea & PC2-rea & PC3-rea \\
\hline NAO1 & -0.46 & - & - & -0.41 & - & - \\
NAO-DJF & -0.49 & - & - & -0.60 & - & - \\
EA1 & 0.42 & - & - & 0.41 & - & - \\
PNA11 & -0.39 & - & - & -0.37 & - & - \\
EAWR-DJF & - & -0.44 & 0.45 & - & - & - \\
SCAND10 & - & - & & & & \\
\end{tabular}

Negative values were obtained in the north and positive values in the south. The results obtained by Nieto et al. (2004) characterize the gradient of precipitation between north (positive values) and south (negative values).

In the study of annual precipitation in the Iberian Peninsula, Rodríguez-Puebla et al. (1998) obtained higher values toward the south-western part of Iberia and lower values in the north.

The EAWR teleconnection index is used to obtain meanings of the second mode of precipitation variability.
The results of the correlation between the precipitation and winter EAWR (EAWR-DJF) indicate that the winter EAWR is correlated with the second principal component and the correlation coefficient is -0.44 (for observed data) and -0.46 (reanalysis data) (Table III). According to the results obtained by Nieto et al. (2004), the precipitation variability in the northern part of the Iberian Peninsula, represented by PC2, is related to the EAWR.

The third eigenvector corresponds to an eigenvalue of 5.3 and $9.9 \%$ for observed and reanalysed data 
respectively. The EOF3 pattern for both data shows the highest values over the south-eastern area of the DB in the Central mountain system and the lowest values in the north-west corner of the DB and north, south of Cantábrico mountain system and east of GalaicoPortuguese mountain system (Figures 4(c) and 5(c)).

The pattern obtained by Rodríguez-Puebla et al. (1998) divides the Iberian Peninsula into west-east precipitation regimes, with higher values toward the east and lower values toward the north-west. The PC3 is positively correlated with October-SCAND (SCAND10) (Table III).

In addition to the relationships between precipitation and teleconnection indices, there are other reasons for the behaviour of the precipitation. The spatial distribution of rainfall, as well as its seasonal variability, may be explained in terms of the broad characteristics of the global circulation and regional climate factors, e.g. latitude, orography, and oceanic and continental influences (Trigo and DaCamara, 2000). Egido et al. (1991) analysed the precipitation over the Spanish Tagus River basin as a function of topographic factors and the results suggest a greater influence of elevation. RodríguezPuebla et al. (1998) obtained the relationships between the annual patterns of precipitation variability and geofactors. An interpretation of the patterns obtained for the winter precipitation in DB also takes into account the relationship between winter months and orographic influences. The topographic factors must also be considered to characterize the winter precipitation variability. Table IV shows the correlation between the winter patterns of precipitation variability and elevation, latitude and longitude.

The EOF1 pattern is strongly linked to rainy months, when westerly advection brings moist air and produces precipitation. This precipitation is intensified by the passage of cold fronts associated with families of transient depressions (Trigo and DaCamara, 2000) and by the orography of the region. In this case, the mountains that separate coastal and inland sites play an important role as blocking factor. The inner basin is protected against Atlantic advections by the mountainous systems. Zorita et al. (1992) assumed that the first EOF pattern of winter precipitation in the Iberian Peninsula is associated with the strength of the mean westerly winds adverting precipitation synoptic systems to Iberia or with the sea surface temperature at the coast. Therefore, the NAO is strongly related to the strength of westerly winds (Trigo et al., 2004).

To quantify the effect of westerly advection, Ulbrich et al. (1999) obtained a highly linear relationship $(r=$

Table IV. Correlation coefficients between EOFs of observed winter precipitation and topographic factors.

\begin{tabular}{lrrr}
\hline Factors & EOF1 & EOF2 & EOF3 \\
\hline Latitude & -0.39 & 0.70 & -0.59 \\
Longitude & -0.53 & 0.01 & 0.50 \\
Elevation & 0.51 & -0.55 & 0.01 \\
\hline
\end{tabular}

0.81) between the first principal component of precipitation in Portugal and north-south sea level pressure gradient over Portugal for individual winter months. They found a correlation maximum of rainfall and local upper air geopotential height variability (the storm track) over Portugal.

EOF2 is positively correlated with the latitude of the region: maximum values correspond to the northeastern zone. Possibly, this pattern could be linked to cyclonic activity that originated in the Mediterranean basin (Zorita et al., 1992). This assumption is reinforced by the fact that the highest coefficients are obtained for the Cantábrico mountain system.

With regard to the different sign of correlation between EOF1 and EOF2 with elevation (Table IV), these relationships are not the simple precipitation enhancement due to the elevation, i.e. precipitation increases with elevation. According to Prudhomme and Reed (1998), the relationship between precipitation and topography, and especially elevation, has been moderated by a secondary phenomenon, the rain-shadow effect. Furthermore, the spatial distribution of precipitation does not depend on elevation in a simple manner, but reflects more complex relationships between relief and position to moisture source (Prudhomme and Reed, 1998).

The smaller scale of EOF3 is difficult to interpret in simple physical terms. The higher variability in the eastern area probably is due to the orography and to the effect of the distance of the shores.

The patterns obtained with observed data have been compared to the corresponding reanalysis data. An examination of the results shows that, in the case of EOF1, both patterns represent the variability of winter precipitation in the direction of the western zone of the basin. An inspection of Figures 4(b) and 5(b) reveals that these patterns divide the study area into a north region (where the loadings are the highest) and a south region (where the loadings are the lowest). In the patterns shown in Figure 4(c) and in Figure 5(c), the maximum loadings are recorded in the south-east zone, while the minimum is recorded in the north-western and north sectors of the DB.

Finally, it is interesting to observe that patterns obtained with observed data have very similar spatial distributions to those obtained with reanalysis data. In both cases, the PCs of winter precipitation corresponding to the observed and reanalysis data are linked to the same teleconnection indices. This result suggests that reanalysis data are suitable for analysing climate variability and climate dynamics in the DB.

\subsection{Intra-annual variation of precipitation}

Using the S-mode of PCA in 10-DDV, some characteristics of the intra-annual variation of precipitation are revealed. The scree test showed that the number of EOFs to retain is two.

The first EOF captures $56.3 \%$ of the total variance. A marked longitudinal trend is shown by EOF1 with 
negative values in the eastern part of the basin and positive values in the western area (Figure 6(a)). This pattern divides the DB into west-east regimes. The loadings exceed 0.7 in the western area of the basin and it means that zone represents the first mode of intra-annual variation.

The temporal coefficients are plotted in Figure 6(b). The intra-annual variation shows one maximum. This maximum extends from mid October to early April. The minimum is recorded in summer. It appears in late May and extends up to September.

The second component explains $30.8 \%$ of the total variance. High loadings appear in the inland zone of DB decreasing toward the west (Figure 7(a)). In this area, the intra-annual variation of the precipitation amounts presents two maxima and a wide minimum. The first maximum appears in late February. The second maximum spans from early April to June and appears about three months later than in PC1. This maximum is especially observed in the central DB region, probably due to the heating of land that favours convection air mass and local storms that generate precipitation. The minimum extends from mid July to early February (Figure 7(b)).

\subsection{Spatial distribution of precipitation}

The T-mode of PCA applied to 10-DDV of precipitation reveals the seasons of the year from a precipitation point of view with similar spatial patterns. The first EOF explains $53.2 \%$ of total spatial variance of precipitation (Figure 8). The spatial distribution of precipitation is characterized by high values in the western and northern areas, decreasing toward the south-eastern region.

Table V shows the factor loadings for the analysis of the spatial distribution of precipitation. These results suggest that PC1 is closely associated with the October $10-\mathrm{DDV}$ to the first 10-DDV of April. The maxima loadings are those of December and January, when all of them exceed 0.95. This period (October-early April) can be associated with the winter season, when the DB is mainly exposed to the influence of Atlantic advections that generate precipitation. The effects of these advections are mitigated in the inland and eastern areas of DB due to the sheltering effect of different mountain ranges. Furthermore, in these zones the effects of frontal precipitation are not so intense because the fronts coming from the Atlantic are weakened by their trajectories.

The second EOF accounts for $33.7 \%$ and comprises mainly the 10-DDV of April to the first 10-DDV of August. The most typical 10-DDV are the first and second of May, when loadings exceed 0.97. During this season, the pattern is characterized by high values in the inland and eastern areas, whereas the lowest values are recorded in the western area of the basin (Figure 9). This period (April-August) can be associated with later spring/summer. The precipitation that occurs in April and May is related to the intense heating of land that leads to air convection and thunderstorms.

The third EOF captures $8.8 \%$ and refers to the period from late August to September, with the maximum at the
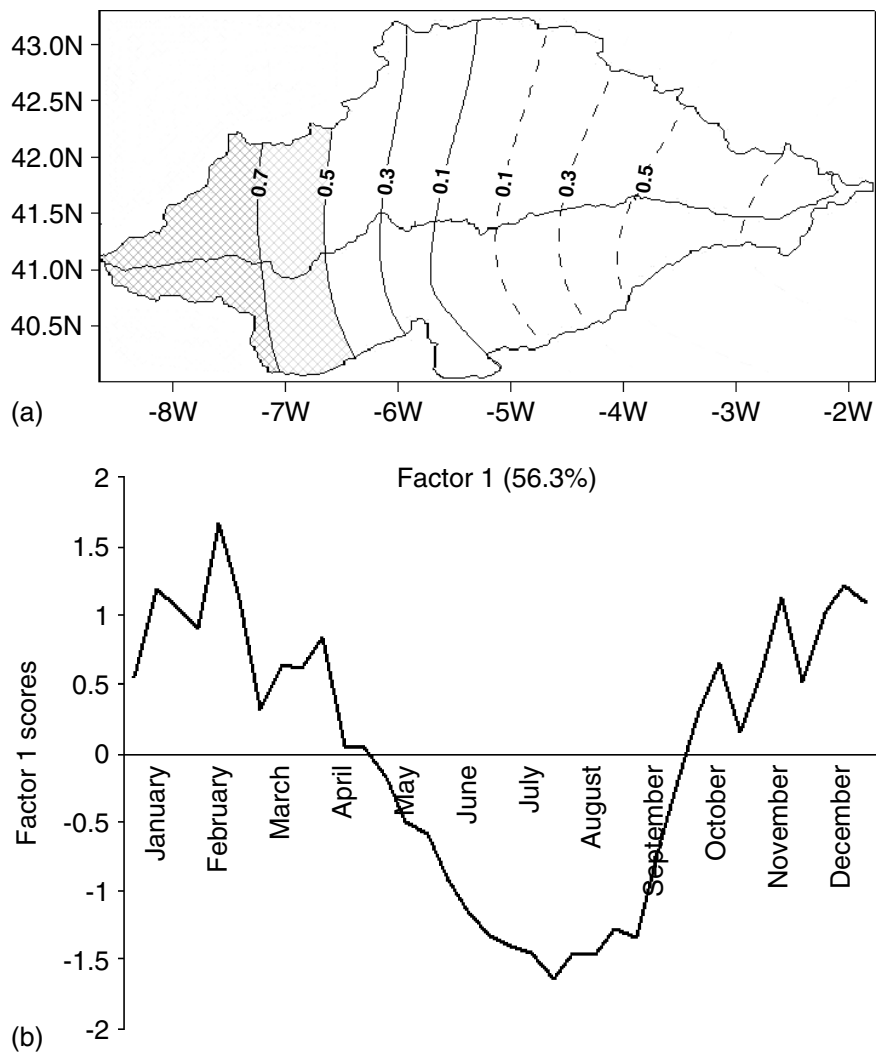

Figure 6. (a). EOF1 of 10-DDV reanalysis data; (b) Time series of PC1 of 10-DDV reanalysis data. 

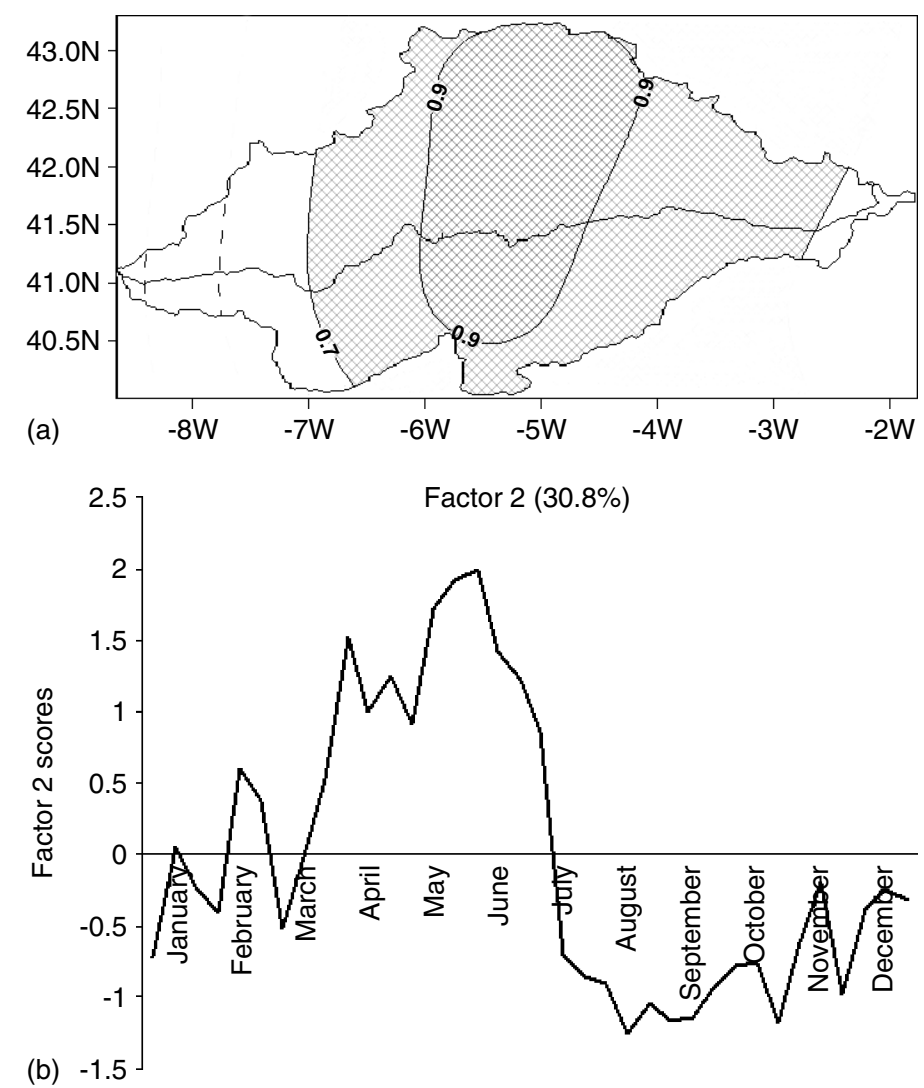

Figure 7. (a). EOF2 of 10-DDV $\nmid$ reanalysis data; (b) Time series of PC2 of 10-DDV reanalysis data.

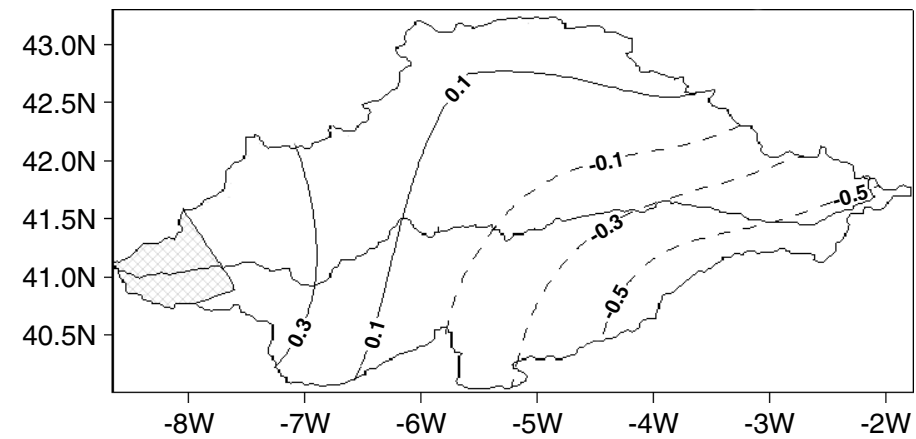

Figure 8. Spatial distribution of precipitation amount. Factor 1 scores.

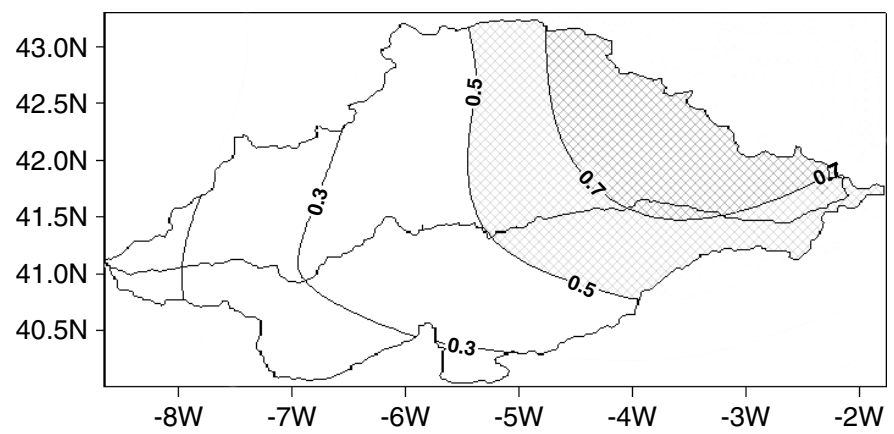

Figure 9. Spatial distribution of precipitation amount. Factor 2 scores. 
Table V. Factor loadings for the analysis on the spatial distribution of precipitation (values lower than 0.32 are not statistically significant at the $95 \%$ confidence level and have been omitted. Values greater than 0.70 indicate that at least $49 \%$ of variance is explained by one factor only and appear in bold).

\begin{tabular}{|c|c|c|c|}
\hline 10-DDV & EOF 1 & EOF 2 & EOF 3 \\
\hline $1^{\text {a }}$ Dec-January & 0.98 & - & - \\
\hline $2^{\mathrm{a}}$ Dec-January & 0.96 & - & - \\
\hline $3^{\mathrm{a}}$ Dec-January & 0.98 & - & - \\
\hline $1^{\text {a }}$ Dec-February & 0.97 & - & - \\
\hline $2^{\mathrm{a}}$ Dec-February & 0.94 & - & - \\
\hline $3^{\mathrm{a}}$ Dec-February & 0.94 & - & - \\
\hline $1^{\mathrm{a}}$ Dec-March & 0.97 & - & - \\
\hline $2^{\mathrm{a}}$ Dec-March & 0.96 & - & - \\
\hline $3^{\text {a }}$ Dec-March & 0.87 & 0.40 & - \\
\hline $1^{\mathrm{a}}$ Dec-April & 0.75 & 0.62 & - \\
\hline $2^{\mathrm{a}}$ Dec-April & 0.45 & 0.86 & - \\
\hline $3^{\mathrm{a}}$ Dec-April & 0.33 & 0.90 & - \\
\hline $1^{\mathrm{a}}$ Dec-May & 0.33 & 0.88 & - \\
\hline $2^{\mathrm{a}}$ Dec-May & - & 0.97 & - \\
\hline $3^{\mathrm{a}}$ Dec-May & - & 0.97 & - \\
\hline $1^{\mathrm{a}}$ Dec-June & - & 0.94 & - \\
\hline $2^{\mathrm{a}}$ Dec-June & - & 0.93 & - \\
\hline $3^{\mathrm{a}}$ Dec-June & - & 0.89 & - \\
\hline $1^{\mathrm{a}}$ Dec-July & - & 0.91 & - \\
\hline $2^{a}$ Dec-July & - & 0.85 & 0.43 \\
\hline $3^{\mathrm{a}}$ Dec-July & - & 0.77 & 0.37 \\
\hline $1^{\text {a }}$ Dec-August & - & 0.73 & 0.61 \\
\hline $2^{\mathrm{a}}$ Dec-August & - & 0.59 & 0.74 \\
\hline $3^{a}$ Dec-August & - & 0.59 & 0.77 \\
\hline $1^{\text {a }}$ Dec-September & - & 0.51 & 0.79 \\
\hline $2^{\mathrm{a}}$ Dec-September & - & - & 0.93 \\
\hline $3^{\mathrm{a}}$ Dec-September & 0.64 & - & 0.72 \\
\hline $1^{\mathrm{a}}$ Dec-October & 0.80 & - & 0.46 \\
\hline $2^{\mathrm{a}}$ Dec-October & 0.89 & - & - \\
\hline $3^{a}$ Dec-October & 0.90 & - & - \\
\hline $1^{\mathrm{a}}$ Dec-November & 0.73 & - & - \\
\hline $2^{\mathrm{a}}$ Dec-November & 0.97 & - & - \\
\hline $3^{\mathrm{a}}$ Dec-November & 0.95 & - & - \\
\hline $1^{\mathrm{a}}$ Dec-December & 0.98 & - & - \\
\hline $2^{\mathrm{a}}$ Dec-December & 0.96 & - & - \\
\hline $3^{\text {a }}$ Dec-December & 0.97 & - & - \\
\hline
\end{tabular}

Note: $1^{\mathrm{a}}$ signifies the first $\left(1^{\mathrm{st}}\right) \mathrm{DDV}, 2^{\mathrm{a}}$ signifies the second $\left(2^{\text {nd }}\right) \mathrm{DDV}$ and $3^{\mathrm{a}}$ signifies the third $\left(3^{\text {rd }}\right)$ DDV.

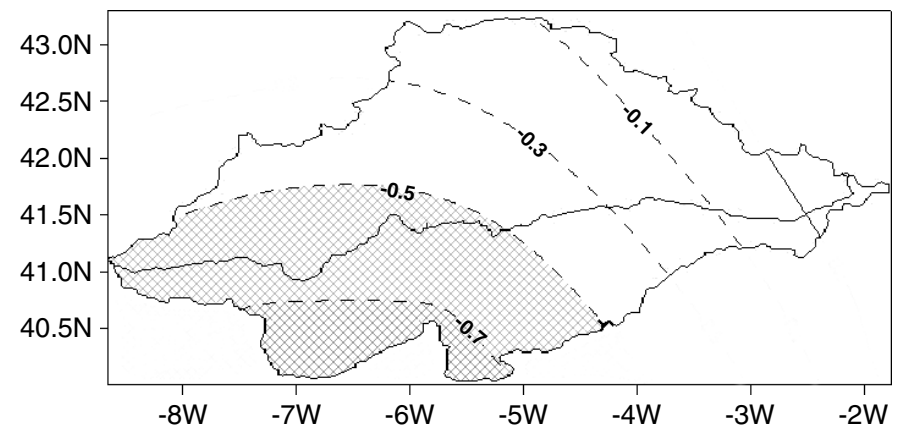

Figure 10. Spatial distribution of precipitation amount. Factor 3 scores. 
second 10-DDV of September. The spatial distribution of precipitation has the maximum located in the eastern corner of the basin, while the minimum is located in the south-western zone of the DB (Figure 10).

This period (end August-September) can be associated with autumn when the precipitation is associated with the gradual displacement of depressions to lower latitudes than in summer.

\section{CONCLUSION}

The results obtained in this study can be summarized as follows:

(1) The winter precipitation variability was studied with PCA and the winter precipitation fields are represented by the first three PCs, which describe 81 and $87 \%$ of the total variance, for both data, respectively. The first mode of variability represents the winter precipitation variability toward the western area of the basin. The second component characterizes the gradient of winter precipitation between north and south and the third component represents the gradient between east and west. The distribution of spatial variability shows agreement between the observed and reanalysis data.

The PC1 data, which represents the precipitation variability toward western regions, are significantly correlated with NAO1, DJF-NAO, EA1 and PNA11. The precipitation variability in the north and northern zones of the DB, represented by PC2, was correlated with EAWRDJF, while PC3, which represents the variability toward the south-eastern areas in the DB region, is linked with SCAND10. Therefore, the reanalysis precipitation data capture the main behaviour of winter over the DB.

The precipitation reanalysis data are a good choice to study the average behaviour and the distribution of spatial and temporal winter variability, as well as climate dynamics over the DB.

(2) The intra-annual variation of precipitation amount was studied applying S-mode on 10-DDV. Over the western area, the intra-annual variation of precipitation amount is characterized by a broad maximum from mid October to early April, probably reflecting the passage of frontal systems typical of this period. During June-August, in the western area of DB, precipitation is a rare event. Over the eastern area, the intra-annual variation of precipitation presents two maxima: the first from late February and the second around April. The first can be attributed to Atlantic advection and the second to local convection air mass. A very long dry period emerges clearly covering the months from August to January.

T-mode of PCA revealed the seasons of the year from a precipitation point of view. The first EOF, with maximum loadings in the western and northern zones of the basin, is associated with 10-DDV of October to the first 10DDV of April. This period can be associated with the winter season. The second EOF showed a maximum in the inland and eastern areas. The most typical 10-DDV is the first and second of May and this pattern can be associated with the spring season. The third EOF with a maximum over the easternmost edge of the basin refers to the period from late August to September. This period is clearly the autumn season.

\section{REFERENCES}

Ardanuy R, Soldevilla MM. 1992. Estadística Basica. Hespérides: Salamanca.

Atchley WR, Bryant EH (eds). 1975. Multivariate Statistical Methods: Among-Groups Covariation. Dowden, Hutchinson and Ross: Stroudsburg.

Barnston AG, Livezey RE. 1987. Classification, seasonality and persistence of low-frequency atmospheric circulations patterns. Monthly Weather Review 115: 1083-1126.

Bartzokas A, Lolis CJ, Metaxas DA. 2003. A study on the intra-annual variation and the spatial distribution of precipitation amount and duration over Greece on a 10 day basis. International Journal of Climatology 23: 207-222.

Browen MW. 1968. A comparison of factor analytic technique. Psychometrika 33: 267-334.

Cahalan RF. 1983. EOF spectral estimation in climate analysis. In Proceedings of Second International Meeting in Statistical Climatology, Lisbon, Portugal 4.1.5-4.5.7.

Cattel RB. 1966. The scree test for the number of factors. Multivariate Behavioral Research 1: 245-276.

Drosdowsky W. 1993. An analysis of Australian seasonal rainfall anomalies: 1950-1987. II: temporal variability and teleconnection patterns. International Journal of Climatology 13: 111-149.

Egido A, Egido M, Seco J, Garmendia J. 1991. Quantitative relationships of mean seasonal precipitation in the Tagus river basin (Spain). International Journal of Climatology 11: 1-8.

Esteban-Parra MJ, Rodrigo FC, Castro-Díez Y. 1998. Spatial and temporal patterns in Spain for the period 1880-1992. International Journal of Climatology 18: 1557-1574.

Fraedrich K, Muller K. 1992. Climate anomalies in Europe associated with ENSO extremes. International Journal of Climatology 12: 25-31.

Goodess CM, Jones PD. 2002. Links between circulation and changes in the characteristics of Iberian rainfall. International Journal of Climatology 22: 1593-1615.

Hogg WD. 1995. Cycles and trends in time series of Canadian extreme rainfall. In Proceedings of Sixth International Meeting in Statistical Climatology, University College, Galway, 247-278.

Hurrel JW, van Loon H. 1995. Decadal Trends in the North Atlantic oscillation and relationships to regional temperature and precipitation. In Proceedings of Sixth International Meeting in Statistical Climatology, University College, Galway Vol. 1, 185- 188 .

Jolliffe IT. 1986. Principal Component Analysis. Springer-Verlag: New York

Kutiel H, Maheras P, Guika S. 1996. Circulation and extreme rainfall conditions in the eastern Mediterranean during the last century. International Journal of Climatology 16: 73-92.

Lana X, Martínez MD, Serra C, Burgueño A. 2004. Spatial and temporal variability of the daily rainfall regime in Catalonia. International Journal of Climatology 24: 613-641.

Marshall J, Kushnir Y, Batisti D, Chang P, Czaja A, Dickson R, Hurrel J, McCartney M, Saravanan R, Visbeck M. 2001. North Atlantic climate variability: phenomena, impacts and mechanisms. International Journal of Climatology 21: 1863-1898.

Matayo I, Semazzi FHM, Ogallo LJ. 2000. ENSO signals in East African rainfall seasons. International Journal of Climatology 20: 19-46.

Nieto S, Frías MD, Rodríguez-Puebla C. 2004. Assessing two different climatic models and the NCEP-NCAR reanalysis data for description of winter precipitation in the Iberian Peninsula. International Journal of Climatology 24: 361-376.

Ninyerola MP, Pons X, Roure JM. 2005. Atlas Climático Digital de la Península Ibérica. Metedologia y Aplicaciones en Bioclimatologia y Geobotánica. Universidad Autónoma de Barcelona: Barcelona.

Peterson T, Easterling DR. 1994. Creation of homogeneous composite climatological referencies series. International Journal of Climatology 14: 671-679. 
Preisendorfer RW. 1988. Principal Component Analysis in Meteorology and Oceanography, Developments in Atmospheric Sciences 17. Elsevier: Amsterdan.

Prudhomme C, Reed D. 1998. Relationships between extreme daily precipitation and topography in a mountainous region: a case study in Scotland. International Journal of Climatology 18: 1439-1453.

Richman MB. 1986. Rotation of principal components. Journal of Climatology 6: 293-335.

Rodó X, Baerrt E, Comin FA. 1997. Variations in seasonal rainfall in Southern Europe during present century: relationships with the North Atlantic Oscillation and the El Niño-Southern Oscillation. Climate Dynamics 13: 275-284.

Rodrigo FS, Esteban-Parra MJ, Pozo-Vásquez D, Castro-Díez Y. 2000. Rainfall variability in southern Spain on decadal to centennial time scales. International Journal of Climatology 20: 721-732.

Rodríguez-Puebla C, Encinas AH, Saénz J. 2001. Winter precipitation over the Iberian Peninsula and its relationships to circulation indices. Hydrology and Earth System Sciences 53: 233-244.

Rodríguez-Puebla C, Encinas AH, Nieto S, Garmendia J. 1998. Spatia and temporal patterns of annual precipitation variability over the Iberian Peninsula. International Journal of Climatology 18 299-316.

Rodríguez-Puebla C, Nieto S, Saénz J, Zubillaga J. 1999. Influences of teleconnection indices on Iberian Peninsula precipitation. In Proceedings of $8^{\text {th }}$ Conference on Climate Variations. American Society: Denver, Co, USA; 129-132.

Saénz J, Zubillaga J, Rodríguez-Puebla C. 2001. Interannual variability of winter precipitation in northern Iberian Peninsula. International Journal of Climatology 21: 1503-1513.
Sneyers R. 1975. Sur l'Analyse Statisque des Séries d'Observations, Note Técnique, 143. Organization Météorologique Mondiale: Genéve.

Sneyers R. 1990. On the Statistical Analysis of Series of Observations, Technical Note, 415. WMO: Genéve.

Trigo RM, DaCamara C. 2000. Circulation Weather Types and their influence on the precipitation regime in Portugal. International Journal of Climatology 20: 1559-1581.

Trigo RM, Pozo-Vázquez D, Osborn TJ, Castro-Díez Y, GámizFortis S, Esteban-Parra MJ. 2004. North Atlantic Oscillation influence on precipitation, river flow and water resources in the Iberian Peninsula. International Journal of Climatology 24: 925-944.

Ulbrich U, Christoph M, Pinto JG, Corte-Real J. 1999. Dependence of winter precipitation over Portugal on NAO and baroclinic wave activity. International Journal of Climatology 19: 379-390.

von Storch H. 1995. Spatial Patterns: EOFs and C.C.A, Analysis of Climate Variability Precipitation. Springer-Verlag: Berlim; 227-257. von Storch H, Zwiers HW. 1999. Statistical Analysis in Climate Research. Cambridge University Press: Cambridge.

Zhou J, Lau KM. 2001. Principal modes of interannual and decadal variability of summer rainfall over South America. International Journal of Climatology 21: 1623-1644.

Zorita E, Kharin V, Storch H. 1992. The Atmospheric circulation and sea surface temperature in the North Atlantic area in winter: their interaction and relevance for iberian precipitation. Journal of Climate 5: $1097-1107$.

Zorita E, Hughes JP, Lettemaier DP, von Storch H. 1995. Stochastic characterization of regional circulation patterns for climate model diagnosis and estimation of local precipitation. Journal of Climatology 8: 1023-1042. 